Artigo Original

\title{
Estratégias de ensino para alunos deficientes visuais: a Proposta Curricular do Estado de São Paulo
}

\author{
Maria Luiza Salzani Fiorini \\ Débora Deliberato \\ Eduardo José Manzini
}

\author{
Faculdade de Filosofia e Ciências. Programa de Pós-graduação em Educação, UNESP - Univ \\ Estadual Paulista... Campus de Marília, Departamento de Educação Especial, Marília, SP, Brasil
}

\begin{abstract}
Resumo: As estratégias e recursos são primordiais para a participação do aluno com deficiência visual nas aulas de educação física. Assim, objetivou-se planejar estratégias de ensino e adaptações de recursos com foco na inclusão educacional do aluno com deficiência visual fundamentando-se nas atividades contidas na Proposta Curricular do Estado de São Paulo. Três etapas foram delineadas a partir da análise da Proposta Curricular: 1) identificar os temas propostos para cada bimestre; 2) analisar o "caderno do professor" em termos de situações de aprendizagem e o desenvolvimento de cada uma delas e, 3) planejar estratégias de ensino e adaptações de recursos. Dez estratégias de ensino foram planejadas, quatro novos recursos foram indicados e duas adaptações de recursos pedagógicos foram sugeridas para as aulas. As atividades da Proposta Curricular permitiram um planejamento de estratégias voltado à participação do aluno com deficiência visual juntamente com alunos sem deficiência.
\end{abstract}

Palavras-chave: Técnicas de planejamento. Materiais. Currículo. Deficientes Visuais.

Strategies for teaching visually impaired students: the Curriculum Proposal of São Paulo State

\begin{abstract}
Strategies and resources are primary to the participation of students with visual impairments in physical education classes. The objective of this study was to plan teaching strategies and resource adaptations focusing on educational inclusion of students with visual impairment based on the activities held in the Curriculum Proposal for São Paulo State. Three steps were outlined from the analysis of the Proposal: 1) identify the subjects for each bimester, 2) analyze the "teacher's book" in terms of learning situations and their development, and 3) plan educational strategies and resource adaptations. Ten teaching strategies were planned, four new resources were indicated and two teaching resources were adapted for the classes. The activities of the Curriculum Proposal allow strategy planning aimed at the participation of students with visual disabilities together with students without disabilities.
\end{abstract}

Keywords: Planning techinques. Materials. Curriculum. Visually Impaired Persons.

\section{Introdução}

O Governo do Estado de São Paulo apresentou, no ano de 2008, uma Proposta Curricular com o objetivo de organizar o ensino em todo o Estado. A Proposta Curricular do Estado de São Paulo propôs um currículo para os níveis de ensino fundamental (ciclo II) e médio com a pretensão de servir como um apoio ao trabalho realizado nas escolas e contribuir para a qualidade da aprendizagem dos alunos (SEE/SP, 2008a).

Especificamente em relação à educação física, a Proposta Curricular do Estado de São Paulo apresentou uma concepção própria sobre a disciplina, com o entendimento de que ela deva tratar pedagogicamente os conteúdos relacionados ao movimentar-se humano, às construções corporais humanas, sendo eles, o jogo, o esporte, a ginástica, as lutas e a atividade rítmica (SEE/SP, 2008a).

Para o ensino fundamental (ciclo II) definiu-se o objetivo de diversificar, sistematizar e aprofundar as experiências do "se movimentar" no âmbito das culturas lúdica, esportiva, gímnica, das lutas e rítmica, de modo a proporcionar novas experiências $e$, também, ressignificação das anteriormente vivenciadas (SEE/SP, 2008a).

A opção por esses conteúdos deu-se porque, por um lado, houve uma ascensão da cultura corporal e esportiva nos meios de comunicação e na economia e, por outro lado, os adolescentes possuíam afinidades com manifestações corporais relacionadas às condições sociais, econômicas e culturais (SEE/SP, 2008a). Assim, a educação física escolar deveria contemplar a cultura corporal que se expressa de diferentes 
formas e em variados contextos, a partir do repertório de conhecimento variado dos alunos e ampliá-lo, aprofunda-lo e qualificá-lo criticamente (SEE/SP, 2008a).

O destaque é para a $7^{a}$ e $8^{a}$ séries do ensino fundamental (ciclo II) (atuais $8^{\circ}$ e $9^{\circ}$ anos) em que o amadurecimento da capacidade do aluno de abstrair e refletir permite avançar no processo de contextualização e fundamentação dos eixos de conteúdos propostos, a partir das dimensões biológicas, sócio-históricas, dentre outras (SEE/SP, 2008a).

Os alunos matriculados nas séries mencionadas anteriormente encontram-se na adolescência, um período de transição entre a infância e a vida adulta, caracterizado por impulsos no desenvolvimento emocional, físico, mental, sexual e social e, por esforços do indivíduo em alcançar objetivos relacionados às expectativas culturais da sociedade em que vive (EISENSTEIN, 2005).

Em termos motores, na faixa etária aproximada dos sete aos 14 anos em diante, o aluno encontra-se na fase motora especializada, em que as habilidades estabilizadoras, locomotoras e manipulativas fundamentais tendem a ser progressivamente refinadas, combinadas e elaboradas para 0 uso em situações mais exigentes (GALLAHUE; OZMUN, 2005).

É preciso ressaltar o princípio da
individualidade, sendo que a sequência de
progressão ao longo dos estágios de
desenvolvimento motor é a mesma para a maioria
das crianças, porém, o ritmo irá variar de acordo
Com os fatores ambientais e hereditários
(GALLAHUE; OZMUN, 2005). Atingir ou não o
estágio amadurecido depende basicamente do
ensino, do encorajamento e das oportunidades
para a prática (GALLAHUE; OZMUN, 2005).

No que diz respeito aos aspectos psicossociais, dos 11 ou 12 anos em diante, na fase da adolescência, ocorre o denominado período operatório formal, em que se pode observar 0 interesse do adolescente por problemas abstratos e a facilidade com que elabora as respectivas teorias, interpreta e verifica as hipóteses, o chamado raciocínio hipotéticodedutivo (PIAGET, 1975). Isso ocorre porque o adolescente passa, aos poucos, a adquirir e dominar a capacidade de abstrair, generalizar, explicar e elaborar teorias (RIZZI; COSTA, 2004).
Em paralelo à elaboração das operações formais, a vida afetiva do adolescente afirma-se com conquistas da personalidade e de inserção na sociedade adulta (RIZZI; COSTA, 2004).

Para efetivar em aula os objetivos da Proposta Curricular, os professores receberam o "caderno do professor", um material organizado por etapa da educação básica, bimestre e disciplina, e que indicava: 1) as orientações sobre os conteúdos do bimestre; 2) uma apresentação teórica dos dois temas a serem trabalhados no bimestre; 3 ) as situações de aprendizagem referente ao tema; 4) o desenvolvimento da situação de aprendizagem dividida em etapas; 5) a atividade avaliadora; 6) a proposta de situações de recuperação e, 7) os recursos para ampliar a perspectiva do professor e do aluno para a compreensão do tema (SEE/SP, 2008b).

Outra distribuição foi do "caderno do aluno" que era compatível com a temática do "caderno do professor" e possuía textos, figuras, gráficos, espaços para os alunos responderem aos exercícios propostos, além de dicas de pesquisas, filmes, livros e sites e também as "lições de casa" (SEE/SP, 2008c).

Com relação às escolas, 0 material da Proposta Curricular foi fornecido sem que as unidades escolares sofressem qualquer tipo de reestruturação física e de recebimento de recursos pedagógicos para atenderem às demandas propostas. A Proposta Curricular implantou-se nas escolas tais como elas se encontravam.

Com o objetivo de identificar a concepção do professor de educação física sobre a Proposta Curricular do Estado de São Paulo, Justo e Corrêa (2012) aplicaram um questionário em 27 professores e chegaram a resultados que indicaram, por exemplo, a "falta de material específico" para seguir a Proposta e a "ausência de uma capacitação para atuar com os conteúdos indicados".

Sabe-se que, na situação escolar real, há alunos com e sem deficiência em um mesmo contexto. É justamente no processo de inclusão do aluno com deficiência que as dificuldades encontradas ao seguir a Proposta Curricular podem agravar-se.

Apesar de toda a organização do material fornecido, não há, no "caderno do professor", orientações sobre como seguir os conteúdos 
propostos quando se tem um ou mais alunos com deficiência matriculados na turma. O professor de educação física não encontra na Proposta Curricular a indicação de estratégias de ensino ou sugestões de recursos pedagógicos e adaptações que possam ser implementadas nas etapas de desenvolvimento de atividades, caso haja um aluno com deficiência na sala.

Salienta-se que tal ausência caminha na contramão do que foi descrito, na própria Proposta Curricular, como obrigação de ser garantido:

[...] igualdade de oportunidades, diversidade de tratamento e unidade de resultados. Quando os pontos de partida são diferentes, é preciso tratar diferentemente os desiguais para garantir a todos uma base comum (SEE/SP, 2008a, p. 15).

Cabe aqui definir o termo estratégia, que

segundo Manzini (2010), é:

[...] uma ação que acontece no momento do ensino ou da avaliação do aluno. Porém, deve ser planejada anteriormente, levando em consideração as características da deficiência, as potencialidades do aluno, o objetivo que se pretende com a realização da atividade e 0 nível de complexidade da atividade exigida (MANZINI, 2010, p. 14).

A estratégia não se resume a passos a serem seguidos exatamente como foram planejados, algo estático, mas, pelo contrário, a estratégia é flexível e passível de ser modificada, caso o professor a identifique como não funcional para 0 aluno (MANZINI, 2010).

Por isso, é indispensável que o professor planeje mais de uma estratégia para a realização de uma única atividade (MANZINI, 2010).

Quanto ao recurso pedagógico, adota-se a definição Manzini e Deliberato (2007) que conceituaram o recurso pedagógico como um estímulo concreto, manipulável e que a esse estímulo seja atribuído uma ou mais finalidades pedagógicas.

Faz-se necessário, também, apresentar o contexto da adaptação nas aulas de educação física em função da inclusão de um aluno com deficiência. Para Rodrigues (2006) adaptar é:

Adequar a exigência da tarefa ao nível de desempenho do executante. Cada vez que se altera a exigência $e$ as condições de desempenho de uma atividade de forma que um dado executante possa realizá-la ou envolver-se num processo de aprendizagem que está sendo adaptada. Tornar uma atividade mais exigente em termos perceptivos, tomada de decisão, desempenho motor ou elaboração cognitiva é também adaptar [...] é o processo de identificação e intervenção sobre variáveis da atividade (executante, tarefa e envolvimento) de forma a tornarem-na mais complexa ou mais simples para ajustarem ao nível de desempenho e desenvolvimento do aprendiz e aos objetivos desejados.

Em se tratando da inclusão de um aluno com deficiência, as adaptações podem ser em relação: 1) ao material e sua organização da aula - tempo, espaço e recursos; 2) ao programa planejamento e atividades; 3) à metodologia estratégias e recursos e, 4) aos conteúdos (BUENO; RESA, 1995 apud CIDADE; FREITAS, 2002).

Quando o processo de inclusão envolve um aluno com deficiência visual, além das adaptações anteriormente citadas, Lieberman e Houston-Wilson (2009) indicaram outras quatro adaptações: 1) modificação nos equipamentos; 2) modificação nas regras; 3) modificação no ambiente e 4) modificação na instrução. É oportuno mencionar que a modificação nas regras e na instrução, citadas por Lieberman e HoustonWilson (2009) como adaptações, também podem configurar-se como estratégias de ensino.

Assim, para o presente trabalho, surgiram duas indagações: 1) quais estratégias de ensino o professor de educação física pode utilizar para seguir a Proposta Curricular do Estado de São Paulo quando há um aluno com deficiência visual em uma turma? 2) Quais recursos podem ser adaptados?

\section{Objetivo}

Identificar as atividades que compõem a Proposta Curricular do Estado de São Paulo para a $8^{a}$ série e, a partir delas, planejar estratégias de ensino e adaptações de recursos com foco na participação do aluno com deficiência visual.

\section{Método}

Para elaborar as estratégias de ensino e adaptações de recursos referentes às atividades que compõem a Proposta Curricular do Estado de São Paulo para a $8^{\underline{a}}$ série, foram necessárias três etapas.

A primeira etapa compreendeu a identificação dos temas propostos para cada bimestre. A partir das informações disponíveis na própria Proposta Curricular para a $8^{\underline{a}}$ série (SEE/SP, 2008a), temse uma síntese dos conteúdos: 
Quadro 1. Temas propostos para a Educação Física - 8ª série

\begin{tabular}{|l|l|l|l|}
\hline \multicolumn{1}{|c|}{$\mathbf{1}^{\circ}$ Bimestre } & \multicolumn{1}{|c|}{$\mathbf{2}^{\circ}$ Bimestre } & \multicolumn{1}{c|}{$\mathbf{3}^{\circ}$ Bimestre } & $\mathbf{4}^{\circ}$ Bimestre \\
\hline Luta: capoeira & $\begin{array}{l}\text { Esporte: modalidade coletiva } \\
\text { a escolher; o esporte na } \\
\text { comunidade e em seu } \\
\text { entorno; espetacularização } \\
\text { do esporte o esporte } \\
\text { profissional; }\end{array}$ & $\begin{array}{l}\text { Esporte: jogo e esporte: } \\
\text { diferenças conceituais e na } \\
\text { experiência dos jogadores; } \\
\text { Modalidade "alternativa" ou } \\
\text { popular em outros países: } \\
\text { rugby, beisebol, badminton, } \\
\text { frisbee, ou outra }\end{array}$ & $\begin{array}{l}\text { Atividade rítmica: } \\
\text { organização de festivais } \\
\text { de dança; }\end{array}$ \\
\hline $\begin{array}{l}\text { Atividade rítmica: } \\
\text { manifestações rítmicas de } \\
\text { diferentes grupos } \\
\text { socioculturais e } \\
\text { manifestações rítmicas } \\
\text { ligadas à cultura jovem }\end{array}$ & $\begin{array}{l}\text { Atividade rítmica: } \\
\text { manifestações rítmicas } \\
\text { ligadas à cultura jovem (hip- } \\
\text { hop, streetdance e/ou outras) }\end{array}$ & $\begin{array}{l}\text { Esporte: organização de } \\
\text { campeonatos; }\end{array}$ & \\
\hline
\end{tabular}

Fonte: Proposta Curricular do Estado de São Paulo (SEE/SP, 2008a).

Diante dos conteúdos, optou-se pelas atividades propostas para o $3^{\circ}$ bimestre "Tema 1 Esporte: jogo e esporte: diferenças conceituais e na experiência dos jogadores".

A segunda etapa compreendeu a análise do "caderno do professor" do ensino fundamental $\left(8^{\mathrm{a}}\right.$ série) no $3^{\circ}$ bimestre (SEE/SP, 2008b), tendo como foco de análise as seguintes partes: 1) apresentação teórica do tema 1 que era "o jogo e esporte"; 2) as situações de aprendizagem referente ao tema $1 \mathrm{e}, 3$ ) o desenvolvimento da situação de aprendizagem.

$E$, na terceira etapa, foram planejadas as estratégias de ensino e as adaptações de recursos, tendo como base a literatura especializada na área de educação física adaptada e de educação especial que indicavam as possíveis mudanças que poderiam ser realizadas em aula, frente à inclusão do aluno com deficiência visual. Inicialmente, o conteúdo teórico presente na Proposta Curricular foi lido. Ressalva-se que o conteúdo pode ser tanto o que deve ser trabalhado em aula teórica, como também, o conteúdo proposto para as aulas práticas. Após a leitura e tendo como base a literatura, foram propostas as estratégias de ensino e as adaptações de recursos para que o mesmo conteúdo possa ser vivenciado por alunos com e sem deficiência.

\section{Resultados}

Por questão de organização e para melhor entendimento e assimilação do material original, o planejamento das estratégias de ensino e adaptações de recursos serão apresentados de acordo com títulos originais da Proposta Curricular do Estado de São Paulo.

\subsection{Tema 1 - Jogo e esporte: diferenças conceituais e experiência dos jogadores}

\subsubsection{Apresentando o tema em aula teórica}

A primeira parte do "caderno do professor" (SEE/SP, 2008b) contém uma apresentação teórica sobre a temática, sendo um conteúdo que deverá ser trabalhado em aula com os alunos. Há também a indicação de algumas perguntas que o professor de educação física pode fazer aos alunos para incentivar a discussão sobre o conteúdo.

Por meio da Proposta Curricular do Estado de São Paulo, os professores de educação física também passaram a ministrar aulas teóricas (FIORINI, 2011).

Algo rotineiro em aulas dentro da sala é que o conteúdo seja escrito na lousa para que os alunos - copiem. Esse costume torna-se perigoso quando há na sala um aluno com deficiência visual. Quando tal situação for uma realidade para o professor de educação física, o conteúdo pode continuar sendo escrito na lousa, mas poderá também ser reproduzido oralmente para o aluno com deficiência visual. A primeira forma de comunicação com um aluno com deficiência visual é a dica verbal (HOUSTON-WILSON et al., 1997).

Outra possibilidade, para as aulas teóricas, é que 0 professor disponibilize o texto escrito na lousa, também, no formato Braille caso o aluno domine esse código (SEABRA JUNIOR; MANZINI, 2008). 
Com relação ao material em Braille é oportuno mencionar que, diante da necessidade da educação brasileira em promover condições de acesso, participação e aprendizagem dos estudantes público alvo da educação especial no ensino regular foram disponibilizadas, no período de 2005 a 2010, 24.301 salas de recursos multifuncionais em escolas da rede municipal, estadual e federal de ensino, o que contemplou $83 \%$ dos municípios brasileiros. Do total de salas implantadas, 23.454 foram do Tipo I e 847 do Tipo II (BRASIL, 2010).

A sala de recursos multifuncionais do tipo 1 contém 14 recursos e a sala do tipo 2 contém 28 recursos, isso porque, agrega recursos de tecnologia assistiva destinados ao atendimento educacional especializado de estudantes com deficiência visual (BRASIL, 2007).

Um detalhe importante nas aulas teóricas é quanto à comunicação verbal. Certas barreiras da aprendizagem do aluno com deficiência visual podem estar relacionadas aos componentes da linguagem a que ele tem acesso nos momentos de exposições orais em sala de aula, uma vez que, 0 uso de recursos extralinguísticos pelo professor como coordenadas espaço-temporais aqui, ali, isto, aquilo - podem impor dificuldades na compreensão dos conteúdos ministrados (LAVARDA; BIDARRA, 2007). O professor precisa estar atento e verificar a linguagem por ele utilizada, para uma aprendizagem mais adequada do aluno com deficiência visual, podendo: 1) verbalizar, em todas as instruções, com voz de comando clara e tranquila para facilitar a percepção do comando solicitado e, 2) explicar os acontecimentos mesmo que pareçam ser comuns e cotidianos (SEABRA JUNIOR; MANZINI, 2008).

Quando há um aluno cego, há outras possíveis estratégias: 1) o próprio professor pode realizar a leitura para o aluno com deficiência, enquanto os demais alunos fazem a cópia e, 2) o professor de educação física pode solicitar o auxílio de um colega de sala para que realize a leitura do que está escrito na lousa para o aluno cego.

Os professores precisam de uma estratégia de ensino que venha a ajudá-los em seu dia a dia da inclusão (BLOCK, 2000). Na educação física, um dos procedimentos pode ser a tutoria (SOUZA, 2009), em que 0 aluno sem deficiência, denominado de colega tutor, auxilia um aluno com deficiência durante as atividades ( $\underline{\mathrm{CRAFT}}$;
LIEBERMAN, 2004; NABEIRO, 2010; ORLANDO, 2010).

As pesquisas têm demonstrado o emprego de colegas tutores nas aulas de educação física quando há alunos com deficiência visual (FIORINI et al., 2008; ORLANDO, 2010; NABEIRO et al., 2011; GODOY et al. 2012), além disso, a divulgação dos procedimentos utilizados para treinar os tutores (BLOCK, 2000; CRAFT; LIEBERMAN, 2004; LIEBERMAN, 2005; KLAVINA; BLOCK, 2008; KLAVINA et al, 2011; RYBOVÁ; SPURNÁ, 2011) e a relevância da tutoria (LIEBERMAN, 2005; MAUERBERGDECASTRO, 2011; MACDONALD; KALEF; REID, 2012).

O modelo tradicional de treinamento de colega tutor foi proposto por Houston-Wilson et al. (1997) e continha três etapas:

1) Recrutamento de tutores: o aluno deve ser voluntário. Não necessariamente este aluno deva ser o mais habilidoso. A idade e o sexo do tutor não interferem;

2) Obter permissão: os pais ou responsáveis pelas crianças que participarem do treinamento devem autorizar tal participação;

3) Sessões de treinamento: os tutores podem ser treinados individualmente ou em grupo. O tempo para as sessões varia de acordo com a faixa etária das crianças. $O$ tipo de deficiência pode interferir na duração do treinamento.

Houston-Wilson et al. (1997) apresentaram quatro componentes para serem utilizados no treinamento para colega tutor:

1) Sensibilização a respeito da deficiência: permitir com que os tutores saibam a respeito da deficiência que o colega de sala apresenta;

2) Técnicas de comunicação: é preciso que os tutores como se comunicar com os alunos com deficiência;

3) Técnicas de ensino: trata-se do "system of least prompts", ou seja, sistema de maior independência no qual objetiva-se a performance do aluno com o mínimo de intervenção. Para tal, faz-se uso de instrução verbal, demonstração, assistência física e feedback;

4) Reforço das técnicas: feedback específico, o ofertando uma informação positiva relacionada a resposta da tarefa; feedback geral, por meio de uma afirmação geral da resposta ou feedback corretivo, na tentativa de modificar uma resposta que está incorreta.

\subsubsection{Utilizando as figura do "caderno do professor"}

Há quatro figuras que ilustram o conteúdo a ser trabalhado em aula teórica, sendo duas de um jogo de taco, uma de um grupo jogando futebol 
em um parque e a figura de uma partida de vôlei (SEE/SP, 2008b, p.10-11).

Para que o professor de educação física possa utilizar estas figuras durante a aula e proporcionar a todos os alunos o acesso ao conteúdo de cada uma delas, é preciso planejar algumas estratégias adequadas. $O$ professor deve escolher o material mais adequado ao seu aluno, variando em níveis de abstrações, tais como, objetos em tamanho real, objetos em miniatura, fotos, figuras coloridas e/ou figuras em branco e preto (MILLIKIN, 1996; BRUNO, 2005).

Ressalta-se que além da figura, o professor de educação física pode apresentar aos alunos o objeto em tamanho real. No caso do jogo de taco, indicado na Proposta Curricular, ao apresentar as figuras, o professor poderá, se possível, providenciar um taco para que o aluno cego possa tatear e conhecer o objeto. Esta estratégia favorece alunos com e sem deficiência uma vez que o aprendizado é potencializado quando se tem contato com o objeto real.

No caso de aluno com baixa visão, o professor de educação física pode encapar o taco com uma fita de cor vibrante (SEABRA; MANZINI, 2008).

Uma segunda estratégia é fazer a descrição de cada uma das figuras. Ao descrever uma figura, a pessoa deve: 1) ser objetiva, isto é, responder à questão "como é o objeto?" 2) ser breve, ou seja, a descrição deve ser o mais concisa possível; 3) ser descritivo, isto é, deve haver o uso de vocabulário amplo, peculiar às pessoas videntes, para descrever as múltiplas características dos objetos (as formas, o tamanho, a textura, a cor, e a disposição dos elementos observados) e 4) ser lógico, ou seja, o início da descrição é feito a partir de uma apreciação genérica do objeto; a seguir, descrever, com detalhes, as várias partes do objeto, em progressão da direita para a esquerda, ou de cima para baixo (TÉCNICAS..., 2009).

Novamente, o professor poderá contar com o auxílio de uma colega de sala - colega tutor - para que faça a descrição da figura para o aluno com deficiência visual.

\subsubsection{Respondendo as perguntas do "caderno do aluno" sobre o tema 1.}

Dependo da dinâmica adotada pelo professor, há a possibilidade de que o "caderno do aluno" (SEE/SP, 2008c) seja respondido em sala de aula. O professor de educação física pode fazer as perguntas oralmente, solicitando que todos os alunos respondam, concretizando uma dinâmica de grupo. Caso as respostas devam, obrigatoriamente, estar registradas no caderno, o professor pode ler a pergunta para o aluno com deficiência visual, ouvir a sua resposta e escrever para ele no caderno, ou ainda, solicitar que o colega tutor registre as respostas no caderno.

No caso das figuras presentes no "caderno do aluno" (SEE/SP, 2008c, p. 3-25), o professor pode utilizar a estratégia de descrição de cada uma das figuras.

\subsection{Situação de aprendizagem 1 - Experimentando as diferenças entre jogo e esporte \\ Nesta parte da Proposta Curricular há um} quadro que sintetiza o tempo previsto em aulas, o conteúdo e temas, as competências e habilidades e por fim, os recursos (SEE/SP, 2008a, p.15).

Quanto aos recursos, poderia haver o acréscimo de alguns que favorecem e ampliem as possibilidades de inclusão do aluno com deficiência visual nas atividades. Poderiam ser acrescentados os seguintes recursos:

- Barbante ou cadarço de tênis: utilizado para as atividades de corrida, uma vez que um pedaço de $30 \mathrm{~cm}$ de barbante pode funcionar como corda-guia (LIEBERMAN; BUTCHER; MOAK, 2001);

- Colchonetes: utilizados para indicar os percursos a serem seguidos durante as atividades (SEABRA JUNIOR; MANZINI, 2008);

- Fita adesiva amarela: utilizada para marcar e delimitar os espaços e objetos (SEABRA JUNIOR; MANZINI, 2008);

- Guizos, papel celofane e sacos plásticos: utilizados para tornar uma bola comum em algo percebido auditivamente. A bola é envolta por alguns sacos plásticos ou papel celofane, ou então, os guizos podem ser colocados dentro das bolas comuns (SEABRA JUNIOR; MANZINI, 2008).

Cabe aqui a explicação de que o barbante é um material comumente encontrado nas escolas e os colchonetes são recursos tradicionais da educação física. Em complemento, as Salas de Recursos Multifuncionais possuem bolas com guizo e bolas de futebol com guizo (BRASIL, 2008). Quanto à fita adesiva amarela seria necessário consultar à direção escolar ou Diretoria de Ensino e verificar a possibilidade de aquisição. 


\subsection{Desenvolvimento da situação de aprendizagem}

\subsubsection{Etapa 1 - O jogo de taco}

$\mathrm{Na}$ etapa 1, é proposto o jogo de taco, em que os alunos devem formar duplas e joga-se em quartetos: uma dupla ataca enquanto a outra defende. A equipe que ataca deve rebater o maior número de vezes a bola lançada pela outra dupla. A dupla que defende tem a incumbência de derrubar o alvo da dupla que ataca. Somente com a derrubada do alvo é que a dupla de defensores adquire o direito de rebater. A cada rebatida bemsucedida na qual a bola viaja para longe, a dupla deve mudar de base e somar dois pontos sucessivamente antes que o lançador retorne á base (SEE/SP, 2008b).

Ao invés de iniciar com o jogo propriamente dito, o professor pode permitir que todos os alunos vivenciem os movimentos necessários no jogo isoladamente. O professor de educação física pode adotar, quando possível, o método de ensino todo-parte-todo, isto é, demonstrar primeiro a habilidade como um todo e depois partes dela, e então ensinar a tarefa toda novamente (SEBRA JUNIOR; MANZINI, 2008).

$\mathrm{O}$ arremesso por cima, executado no jogo de taco, é um movimento que requer coordenação do movimento do braço e do quadril; é preciso que haja uma rotação do quadril conforme 0 braço do arremesso é trazido para trás, e a bola arremessada terá uma trajetória parabólica, sendo que a recepção ocorre acima do solo (GALLAHUE; OZMUN, 2005). Diante das exigências motoras do arremessar e na presença de um aluno com deficiência visual para participar da atividade, o professor de educação física pode modificar a regra do jogo (LIEBERMAN; HOUSTON-WILSON, 2009), substituir este movimento pelo rolamento de bola. A modificação não deve ser apenas para o aluno com deficiência visual, mas para todos os alunos, podendo beneficiar a prática de muitos deles.

A bola utilizada pode ser tanto a com guizo disponível nas Salas de Recursos Multifuncionais, para as escolas que tiverem, ou, os professores podem adaptar a bola, envolvendo-a em sacos plásticos ou papel celofane, ou então, colocar guizos dentro da bola comum o que a tornará perceptível auditivamente (SEABRA JUNIOR; MANZINI, 2008).

Para o aluno com deficiência visual, é preciso que 0 professor de educação física explique verbalmente o movimento do rolamento de bola, lembrando que a primeira forma de comunicação com um aluno com deficiência visual é a dica verbal (HOUSTON-WILSON et al., 1997). Assim, o professor deve orientar o aluno para que mantenha seus pés afastados, na posição de pernas abertas, cada uma a igual distância da bola; a bola deve ser apanhada com as mãos pela lateral e deve estar entre as pernas, é preciso fazer uma inclinação do tronco, seguida de inclinação do braço para a frente e elevação do tronco com a liberação da bola (GALLAHUE; OZMUN, 2005).

Além do rolamento de bola, é preciso que os alunos vivenciem a rebatida de bola. Uma vez que o arremesso foi substituído pelo rolamento, é necessário modificar também a rebatida de bola. Por meio do rolamento, a bola irá fazer um percurso rente ao solo. Sendo assim, não há como executar o rebater com bastão. Desta forma, a bola pode ser rolada em direção ao aluno, que por sua vez, irá aparar a bola com os pés e em seguida impulsiona-la com o taco.

Tais modificações correspondem a uma indicação da Proposta Curricular, ao professor de educação física: "É importante que você, professor, deixe bem flexível a forma como o atacante rebaterá a bola" (SEE/SP, 2008b).

Caso seja necessária complementar a instrução verbal, o professor poderá utilizar a ajuda física, que consiste em levar o aluno a perceber o movimento realizado pelo professor por meio do toque (LIEBERMAN; HOUSTONWILSON, 2009).

Outra opção de trabalho com alunos cegos é o movimento coativo, em que o professor encaixar o aluno em seu colo, com as costas apoiadas no peito do professor, inicialmente sentados (MAUERBERG-DE CASTRO, 2011). A ênfase deve estar nas posturas e expressões faciais, mas também, nos contrastes tônico-musculares do professor sobre o corpo da criança (MAUERBERG-DE CASTRO, 2011).

As mesmas explicações podem ser feitas quanto ao rebater a bola. É possível, então, manter a organização dos alunos em quartetos, entretanto, modificando alguns elementos do jogo.

Diante das características do aluno cego, é interessante que a bola utilizada no jogo (a de iniciação sugerida na Proposta Curricular, por exemplo), contenha guizos em seu interior, ou então, seja envolta em sacos plásticos ou papel celofane, para ser percebida auditivamente (SEABRA JUNIOR; MANZINI, 2008).

No caso de um aluno com baixa visão, a adaptação da bola é no sentido de utilizar bolas 
nas cores laranja ou amarelo, para estimular a prática deste aluno.

Durante a atividade, o professor pode orientar o aluno cego para que ele: 1) ouça a bola vindo em sua direção; 2) apare a bola com os pés e 3) impulsione a bola com o taco.

$\mathrm{Na}$ etapa 1, o professor de educação física pode solicitar o auxílio do colega tutor. Há a possibilidade de identificar os alunos voluntários e alterná-los durante as atividades.

Após a vivência dos movimentos envolvidos no jogo de taco, o professor de educação física pode aumentar a complexidade da atividade e inserir o arremesso de bola e a rebatida com o taco, sendo uma possibilidade para os alunos e não uma imposição, uma vez que pode manter a opção de rolamento de bola. Por fim, o professor de educação física pode propor aos seus alunos o jogo de taco verdadeiramente.

Salienta-se que, se o aluno com deficiência visual teve, nas atividades anteriores, estratégias planejadas e adaptações de recursos, é possível que no jogo ele tenha melhores condições de participação. Antes de iniciar o jogo, explique todas as regras da nova atividade, confirme se todos os alunos entenderam e lembre-os de: 1) usar a bola com guizo ou envolta em saco plástico; 2) priorizar o rolamento de bola ao invés do arremesso; 3) aparar a bola com os pés e em seguida impulsioná-la com o taco. O professor pode, ainda: 1) encurtar o espaço entre o aluno que irá lançar a bola e o aluno com deficiência visual; 2) solicitar que o arremessador avise o aluno com deficiência que irá rolar a bola, por exemplo, "Eu vou jogar", para que ele fique atento ao som.

De acordo com a Proposta Curricular do Estado de São Paulo (SEE/SP, 2008a), no jogo de taco, uma dupla ataca enquanto a outra defende; a dupla que ataca deve rebater o maior número de vezes a bola lançada pela outra dupla; a cada rebatida a dupla deve mudar de base e são contados dois pontos, sendo o objetivo somar 24 pontos e, somente com a derrubada do alvo, é que a dupla de defensores adquire o direito de rebater. $O$ professor de educação física pode modificar as regras do jogo, tornando-o uma atividade em que todos os alunos tenham condições de participar, permitindo a inclusão do aluno com deficiência visual (LIEBERMAN; HOUSTON-WILSON, 2009).

As seguintes regras podem ser estipuladas: 1) o aluno pode aparar a bola com os pés e em seguida impulsioná-la com o taco; 2) o aluno sempre troca de base após a rebatida, mas, apenas uma troca; 3) o jogo não vale 24 pontos para apenas uma dupla, mas sempre que conseguir aparar a bola e impulsioná-la em direção à outra dupla, marca dois pontos para o quarteto; 4) não há alvo para derrubar, é preciso apenas aparar a bola e rebate-la para o colega; 5) quando o quarteto somar 24 pontos inverte ataque com defesa. Resumindo, não há ganhador ou perdedor, mas, o quarteto junto, soma 24 pontos.

Para realizar a atividade anteriormente explicitada, são necessários alguns cuidados para com o aluno com deficiência visual, no momento da troca de base. O colega tutor pode acompanhar o aluno ao longo de toda a atividade, conduzindo-o durante a troca. Todavia, para permitir maior independência do aluno com deficiência visual, é possível que o colega tutor, o professor ou outro colega da sala fiquem parados no local onde o aluno com deficiência visual deve chegar. Além disso, essas pessoas podem bater palmas ou utilizar um chocalho de modo que orientem auditivamente o aluno com deficiência (SEABRA JUNIOR; MANZINI, 2008).

Outra estratégia é que o percurso a ser percorrido pelo aluno seja cercado por colchonetes, os quais definiram a área de jogo (SEABRA JUNIOR; MANZINI, 2008).

Se o aluno tiver baixa visão, o professor pode traçar uma linha reta, com fita amarela, indicando o caminho, além de colocar um cone, encapado com fita amarela, para sinalizar o final do trajeto (SEABRA JUNIOR; MANZINI, 2008).

O professor pode manter a sugestão que segue na Proposta Curricular, de conduzir uma discussão com o grupo ao final das atividades (SEE/SP, 2008b). Todas as estratégias e adaptações realizadas podem ser discutidas, indagando os alunos sobre ampliação das possibilidades de participação. É relevante que o aluno com deficiência visual seja incentivado a participar.

\subsubsection{Etapa 2 - O jogo "base quatro"}

$\mathrm{Na}$ etapa 2, está previsto o jogo "base quatro". Basicamente, são formadas duas equipes, elas atacarão e defenderão em tempos diferentes. $O$ professor é orientado a desenhar quatro bases no chão, dispostas cerca de cinco metros umas das outras, formando um quadrado. O objetivo do jogo é conquistar as quatro bases, tocando-as com os pés. A equipe que ataca deve rebater a bola lançada por um membro da equipe defensora. $O$ aluno que rebater deverá percorrer as quatro 
bases, mas, se após rebater a bola, ele chegar à primeira base e perceber que a bola está chegando ao arremessador, deve permanecer naquela base e esperar o próximo rebatedor de sua equipe, para poder dar continuidade à conquista das demais bases. A cada volta dada por um atacante (conquista das quatro bases), é somado um ponto para sua equipe. Todos os membros da equipe devem rebater uma vez, e em seguida passam a defender. A equipe que defende tem por objetivo buscar a bola e devolvela ao lançador antes que o atacante chegue à primeira base ou passe por todas. Se o defensor passar a bola para o lançador antes que o atacante chegue à base, esse estará eliminado (SEE/SP, 2008b).

Inicialmente o professor de educação física pode montar as quatro bases. Se houver um aluno com baixa visão, é interessante usar cones coloridos ou encapados de fita em cor brilhante, como base (SEABRA JUNIOR; MANZINI, 2008).

No momento da explicação do jogo, o professor de educação física precisa estar atento à quantidade e a qualidade das informações transmitidas aos alunos, diferenciando os estímulos e números de informações a serem dadas a jogadores iniciantes frente a jogadores experientes (SEABRA JUNIOR; MANZINI, 2008). Assim como na aula teórica, o professor precisa verificar a linguagem por ele utilizada.

O colega tutor, que irá acompanhar o aluno com deficiência visual na atividade, pode levá-lo para explorar o ambiente, isto é, o percurso das quatro bases (SEABRA JUNIOR; MANZINI, 2008).

Para a realização do jogo, é possível seguir a orientação contida na Proposta Curricular, a qual indica que os alunos devem formar duas equipes (SEE/SP, 2008b). O jogo "base quatro" envolve as habilidades motoras trabalhadas na etapa anterior, no jogo de taco, sendo assim, podem ser utilizadas as mesmas estratégias do jogo de taco, desde que tenham sido avaliadas pelo professor como favoráveis à participação dos alunos.

Especificamente em relação ao aluno com deficiência visual, é imprescindível a manutenção das estratégias planejadas para o jogo de taco, caso tenham auxiliado o aprendizado do aluno, haja vista que na etapa 1 , ele vivenciou o jogo de acordo com as mesmas adaptações. Caso as estratégias não tenham sido adequadas na etapa 1, o professor pode mudar as que julgar necessárias.

Como explicado anteriormente, após a rebatida da bola, os alunos devem correr em direção à primeira base. Para que o aluno com deficiência visual siga esta regra do jogo, há três estratégias: 1) o colega tutor, o professor ou um aluno que esteja próximo à primeira base, podem bater palmas, orientando a trajetória ou utilizar um chocalho, de modo que orientem auditivamente 0 aluno com deficiência (SEABRA JUNIOR; MANZINI, 2008); 2) o colega tutor e o aluno com deficiência visual podem estar unidos por meio de uma corda-guia, um recurso para corridas (LIEBERMAN; BUTCHER; MOAK, 2001); 3) o percurso a ser percorrido pelo aluno pode ser cercado por colchonetes, os quais definiram a área de jogo (SEABRA JUNIOR; MANZINI, 2008); 4) se o aluno tiver baixa visão, o professor pode traçar uma linha reta, com fita amarela, para indicar o caminho (SEABRA JUNIOR; MANZINI, 2008)

De acordo com a regra oficial do jogo, o aluno rebatedor deverá percorrer as quatro bases, podendo conquistá-las uma a uma ou as quatro em uma só corrida. Pelas próprias características do jogo, os alunos tendem a querer conquistar todas as bases de uma só vez e somar o ponto para sua equipe. Porém, quando há um aluno com deficiência visual na turma, as estratégias propostas podem fazer com que a execução da atividade leve mais tempo. Por isso, o professor pode fazer mais uma modificação na regra do jogo: o aluno rebatedor deverá conquistar uma base por vez. Isto é, ele rebate a bola, conquista a primeira base e deve permanecer naquela base e esperar o próximo rebatedor de sua equipe para poder dar continuidade à conquista das demais bases.

Novamente, propõem-se uma discussão final, assim como está previsto na Proposta Curricular.

\subsubsection{Etapa 3 - "Base quatro com regras fixas"}

$\mathrm{Na}$ etapa 3 é proposto um jogo com maior nível de complexidade. O professor é orientado a enfatizar as regras e não flexibiliza-las, justamente porque a etapa 3 tem como propósito exemplificar e enfatizar a diferença entre jogo e esporte, devendo haver uma reflexão sobre os limites que as regras impõem aos jogadores e a necessidade do melhor desempenho para a execução das ações (ㅌEE/SP, 2008b).

Todavia, as "regras fixas" podem ser estipuladas pelos alunos e pelo professor de educação física e podem ser, justamente, as regras modificadas em função das etapas 1 e 2 .

De acordo com o "caderno do professor" (SEE/SP, 2008b), os alunos devem formar duas 
equipes, ataque e defesa, sendo que na equipe defensora deve existir uma divisão de função entre os membros "buscadores de bola, passadores de bola e os arremessadores".

Ao longo do jogo, o professor pode criar oportunidades para que todos os alunos vivenciem as três funções. Precisamente em relação ao aluno com deficiência visual, o professor precisa estar atento à atividade que 0 aluno vai realizar, isto é: 1) quando ele for "buscador de bola", imagina-se que irá correr bastante e em várias direções, neste caso, podese manter o acompanhamento do colega tutor $e$ também da corda guia; 2) quando ele for "passador de bola", é interessante manter as regras das etapas anterior, as quais o aluno que for lançar a bola para o aluno com deficiência visual deve, inicialmente, avisar que irá lançar e esse lançamento deve ser por meio de um rolamento de bola e 3) quando o aluno com deficiência visual for "arremessador", a sua equipe pode orienta-lo, por meio de dica verbal, a respeito da direção do lançamento.

Segundo as instruções contidas na Proposta Curricular, cada aluno da equipe atacante tem apenas três chances para rebater uma bola "boa", lançada pela equipe defensora, sendo o professor de educação física o responsável por determinar qual bola é considerada "boa" ( $\underline{\mathrm{SEE} / \mathrm{SP}}, 2008 \mathrm{~b})$. Há a possibilidade de que a regra das três chances para rebater uma bola "boa" seja modificada, ao passo que cada aluno rebatedor continue com as três chances para acertar uma bola. Porém, esta bola será lançada de modo alternado, por exemplo, o primeiro lançamento será um rolamento de bola, o segundo um arremesso por cima e, o terceiro e último será novamente um rolamento de bola. As duas opções de lançamento também foram propostas nas etapas 1 e 2, e na etapa 3. O aluno tem as duas opções de lançamento, devendo acerta uma delas, para que inicie a conquista das bases.

Além disso, a Proposta Curricular indicou a possibilidade de que um aluno seja eliminado da atividade, porque não conseguiu rebater a bola "boa" ou porque ao correr pelas bases, elas estavam fechadas - a bola chegou antes ao arremessador (SEE/SP, 2008b). É possível enumerar os alunos, de modo que, seguindo a ordem, todos os alunos sejam rebatedores e, se o aluno acertar a rebatida, prossegue na conquista das bases, se não acertar, terá nova chance após o último aluno enumerado.

Para que a atividade mantenha as características de "regras fixas" e enfatizar a diferença entre jogo e esporte, além do lançamento de bola alternado entre rolamento e arremesso por cima, é possível acrescentar uma nova regra: os rebatedores devem alternar entre menino e menina e a regra pode valer, também, para os arremessadores, incentivando a prática de todos os alunos e diminuindo as chances de que os meninos excluam as meninas.

Todas as estratégias planejadas para as etapas anteriores podem ser mantidas na etapa 3. Cabe ao professor discernir quais foram adequadas e contribuíram para o aprendizado e participação do aluno com deficiência, e de todos os outros.

\section{Conclusões}

As atividades do tema 1 permitiram um planejamento de estratégias de ensino voltado à participação do aluno com deficiência visual juntamente com alunos sem deficiência. Destacase que foram planejadas 10 diferentes estratégias de ensino que podem ser seguidas, nas diferentes situações de aprendizagem, pelos professores de educação física para trabalhar o tema 1.

Tais estratégias dizem respeito: 1) à comunicação: usar a dica verbal para explicações e verificar a linguagem utilizada, sendo claro e objetivo, evitando uso de coordenadas espaçotemporais; 2) ao uso de material em Braille; 3 ) ao auxílio e técnicas de treinamento do colega tutor; 4) ao uso de objetos reais para explicar a atividade; 5) à descrição de figuras; 6 ) ao método de ensino todo-parte-todo; 7) à modificação das regras do jogo; 8) à orientação do trajeto a ser percorrido pelo aluno: auditivamente, por exemplo, bater palmas ou usar chocalhos, ou então, com colchonetes; 9) à exploração do ambiente de aula e, 10) ao uso da corda-guia para atividades de corrida.

Com relação aos recursos pedagógicos, foi sugerido o uso de alguns que não estão arrolados na Proposta Curricular, como colchonetes, fita adesiva amarela, guizos, papel celofane e sacos plásticos. As adaptações sugeridas foram para: 1) a bola, no sentido de torná-la perceptível auditivamente, seja envolvendo-a em papel celofane e/ou sacos plásticos, ou então, colocando guizos em seu interior e, 2) ao cone, que pode ser colorido ou encapado com cores vibrantes.

É relevante mencionar que as estratégias de ensino são flexíveis e, por isso, o professor deve discernir quais são adequadas e contribuem para a participação dos alunos com e sem deficiência. As estratégias podem ser mantidas desde que tenham sido avaliadas, pelo professor, como favoráveis à participação dos alunos. 


\section{Referências}

BLOCK, M. E. A teacher's guide to including students with disabilities in general physical education. 2. Ed. Baltimore: Paul H. Brookes, 2000.

BRASIL. Ministério da Educação. $\mathbf{O}$ que foi feito. Implantação de Salas de Recursos Multifuncionais. 2010. Disponível em: < http://gestao2010.mec.gov.br/o que foi feito/prog ram 70.php>. Acesso em: 03 nov. 2012.

BRASIL. Ministério da Educação. Secretaria de Educação Continuada. Documento orientador programa implantação de salas de recursos multifuncionais. 2008.

BRASIL. Ministério da Educação. Secretaria de Educação Especial. Programa de implantação de salas de recursos multifuncionais. Edital $n^{\circ}$ 01, de 26 de abril de 2007.

BRUNO; M. M. G. Avaliação educacional de alunos com baixa visão e múltipla deficiência na educação infantil: uma proposta de adaptação e elaboração de instrumentos. 2005. 157f. v. 2.Tese (Doutorado em Educação) Faculdade de Filosofia e Ciências, Universidade Estadual Paulista, 2005.

CIDADE, R. E. A.; FREITAS, P. S. Introdução à educação física e ao desporto para pessoas portadoras de deficiência. Curitiba: Ed. UFPR, 2002.

CRAFT, D. H.; LIEBERMAN, L.J. Deficiência visual e surdez. In: WINNICK, J. P. Educação física e esportes adaptados. Barueri: Manole, 2004. p. 181-206.

EISENSTEIN, E. Adolescência: definições, conceitos e critérios. Adolescência \& Saúde, Rio de Janeiro, v.2, n.2, p.6-7, 2005. Disponível em: < http://www.adolescenciaesaude.com/detalhe artig o. asp?id=167 > . Acesso em: 04 nov. 2012.

FIORINI, M. L. S. Concepção do professor de Educação Física sobre a inclusão do aluno com deficiência. 2011. 143 f. Dissertação (Mestrado em Educação) - Faculdade de Filosofia e Ciências, Universidade Estadual Paulista, Marília, 2011.

FIORINI, M. L. S. et al. Inclusion of students with disabilities in regular physical educations classes, city of Bauru, Brazil. In: EUCAPA - Sciences and APA for everybody, 2008, Torino. Abstracts... Torino: SUISM, 2008. p. 121-121.

GALLAHUE, D. L., OZMUN, J. C. Compreendendo o desenvolvimento motor: bebês, crianças, adolescentes e adultos. 3.ed. Tradução de Maria Aparecida da Silva Pereira Araujo. São Paulo: Phorte, 2005.

GODOY, M. R. B. Performance of the peer tutor of a student with visual impairments in regular physical education classes. In: NORTH AMERICAN FEDERATION OF ADAPTED PHYSICAL ACTIVITY (NAFAPA), 11., 2012. In: Abstracts... Alabama: NAFAPA, 2012. p. 51.

HOUSTON - WILSON, C. et al. Peer tutoring: a plan for instruction students of all abilities. Brazilian International Journal Adapted Physical Education Research, v. 68, n. 6, 1997.

KLAVINA, A. et al. Cooperation-oriented learning using peers tutorsfor increased involvement in physical education. In: INTERNATIONAL SYMPOSIUM ON ADAPTED PHYSICAL ACTIVITY (ISAPA), 18, 2011, Paris. Book of abstracts... Paris: Inshea, 2011. p.99.

KLAVINA, A.; BLOCK, M. The effect of peer tutoring on interaction behaviors in inclusive physical education. Adapted Physical Activity Quarterly, Champaign, v.25, n.2, p132-158, 2008.

JUSTO, M. R.; CORRÊA, E. A. Proposta curricular do Estado de São Paulo: Educação Física escolar em questão. EFDeportes.com Revista Digital, Buenos Aires, ano 15, № 166, p.1-1, 2012. Disponível em: <

http://www.efdeportes.com/efd166/propostacurricular-educacao-fisica-escolar.htm> . Acesso em: 05 nov. 2012.

LAVARDA, S. T. F.; BIDARRA, J. A Dêixis como um "complicador/facilitador" no contexto cognitivo e lingüístico em ambiente educacional face aos alunos com deficiência visual. Revista Brasileira de Educação Especial, Marília, v.13, n.3, p. 309324, 2007.

LIEBERMAN, L. J. Visual Impairments. In: WINNICK, J. P. (Ed.). Adapted physical education an sport. 4th ed. New York: College at Brackport: Human Kinetics, 2005. p.205-220.

LIEBERMAN, L. J.; BUTCHER, M.; MOAK, S. A study of guide - running techniques for children who are blind. Palaestra, Summer, p. 20-26, 2001.

LIEBERMAN, L. J.; HOUSTON - WILSON, C. Strategies for inclusion: a handbook for physical educators. 2.ed. Champaign: Human Kinetics, 2009.

MACDONALD, C.; KALEF, L.; REID, G. Evidence - based practice: a quality indicator analysis of peer-tutoring in adapted physical education. In: NORTH AMERICAN FEDERATION OF 
ADAPTED PHYSICAL ACTIVITY (NAFAPA), 11., 2012. In: Abstracts... Alabama: NAFAPA, 2012. p.95.

MANZINI, E. J. Recurso pedagógico adaptado e estratégias para o ensino de alunos com deficiência física In: MANZINI, E. J.; FUJISAWA, D. S. Jogos e recursos para comunicação e ensino na educação especial. Marília: ABPEE, 2010. p. 117-138.

MANZINI, E. J.; DELIBERATO, D. Portal de ajudas técnicas: equipamento e material pedagógico para educação - recursos adaptados II. Brasília: ABPEE/MEC/SEESP, 2007.

MAUERBERG-DECASTRO, E. Atividade física adaptada. 2.ed. Ribeirão Preto: Tecmed, 2011.

MILLIKIN, C. C. Symbol systems and vocabulary selection strategies. In: GLENNEN, S. L.; DE COSTE, D. C. Handbook of augmentative and alternative communication. São Diego: Singular Theomson Learning. 1996; p. 97-148.

NABEIRO, M. O colega tutor nas aulas de educação física inclusiva. In: MENDES, E. G.; ALMEIDA, M. A. (Org.). Das margens ao centro: perspectivas para as políticas e práticas educacionais no contexto da educação especial inclusiva. Araraquara: Junqueira \& Marin, 2010.

NABEIRO et al. Analysis of the inclusion process of a student with physical disability in physical education classes: case study. In: INTERNATIONAL SYMPOSIUM ON ADAPTED PHYSICAL ACTIVITY (ISAPA), 18., 2011, Paris. Book of abstracts... Paris: Inshea, 2011. p.70.

ORLANDO, P. A. O colega tutor de alunos com deficiência visual nas aulas de Educação Física. 2010. 75f. . Dissertação (Mestrado em Educação Especial) - Universidade Federal de São Carlos, São Carlos, 2010.

PIAGET, J. A construção do real na criança. 2.ed. Rio de Janeiro: Zahar, 1975.

RYBOVÁ, L; SPURNÁ, M. Peer tutoring in general education setting. In Czech Republic. In: INTERNATIONAL SYMPOSIUM ON ADAPTED PHYSICAL ACTIVITY (ISAPA), 18., 2011, Paris. Book of abstracts... Paris: Inshea, 2011. p.245.

RIZZI, C. B.; COSTA, A. C. R. O período de desenvolvimento das operações formais na perspectiva piagetiana: aspectos mentais, sociais e estrutura. EDUCERE, Umuarama, v.4, n.1, p. 29-42, 2004. Disponível em: < http://revistas.unipar.br/educere/article/view/178/1 52>. Acesso em: 04 nov. 2012.
RODRIGUES, D. As dimensões de adaptação de atividades motoras. In: RODRIGUES, D.

Atividade motora adaptada: alegria do corpo.

São Paulo: Artes Médicas, 2006. p. 63-79

SEABRA JUNIOR, M. O.; MANZINI, E. J. Recursos e estratégias para o ensino do aluno com deficiência visual na atividade física adaptada. Marília: ABPEE, 2008.

\section{SECRETARIA DO ESTADO DA EDUCAÇÃO (SEE). Proposta Curricular do Estado de São \\ Paulo: Educação Física. São Paulo: SEE, 2008a.}

SECRETARIA DO ESTADO DA EDUCAÇÃO (SEE).. Caderno do professor: educação física, ensino fundamental - $8^{\mathrm{a}}$ série, $3^{\circ}$ bimestre. São Paulo: SEE, 2008b.

\section{SECRETARIA DO ESTADO DA EDUCAÇÃO} (SEE). Caderno do aluno: educação física, ensino fundamental - $8^{a}$ série, $3^{\circ}$ bimestre. São Paulo: SEE, 2008c.

SOUZA, J. V. A tutoria: estratégia de ensino para inclusão de alunos com deficiência visual nas aulas de educação física. In: CONGRESSO BRASILEIRO DE CIENCIAS DO ESPORTE, 16., 2009, Salvador. Anais..., Salvador: CBCE, 2009.

TÉCNICAS de descrição de imagem para sítios web de museus. 2009. Disponível em: $<$ http://www.acesso.umic.pt/museus/imgmuseus.h tm>. Acesso em: 28 jul. 2009.

Apoio financeiro: CAPES/Proesp

Endereço:

Maria Luiza Salzani Fiorini

Avenida João Gerosa, 761. Bairro dos Francos

Serra Negra SP Brasil 13930-000

Telefone: (19) 9744-2721

e-mail: mazinhasf@yahoo.com.br

Recebido em: 9 de julho de 2011. Aceito em: 4 de fevereiro de 2013.

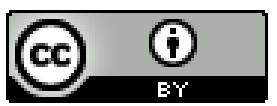

Motriz. Revista de Educação Física. UNESP, Rio Claro, SP, Brasil - elSSN: 1980-6574 - está licenciada sob Creative Commons - Atribuição 3.0 